\title{
Giovan Giorgio Trissino: La Poética. Edición, traducción y estu- dio de Isabel Paraíso. Madrid: Arco/Libros, 2014.
}

El tratado Poetica (1529 y 1562), una de las principales obras en lengua toscana del humanista italiano Giovan Giorgio Trissino (Vicenza, 1478 - Roma, 1550), era accesible hasta ahora a través de la oferta telemática de la casa Google. El estudioso podía acudir también a la edición facsimilar realizada, en 1969, por la editorial alemana Fink (München, Poetiken des Cinquecento). No disponíamos, sin embargo, de una traducción española. Esta es la empresa llevada a cabo por la profesora Isabel Paraíso, Catedrática de Teoría de la Literatura y Literatura Comparada de la Universidad de Valladolid.

La doctora Paraíso había ya publicado en 2010 un esclarecedor trabajo titulado «Giangiorgio Trissino: innovador, poeta y máximo teórico de la métrica italiana renacentista» (Rhythmica, VIII, 111-141), en el que se ponían de manifiesto los aportes y las innovaciones del tratadista en el campo de la Métrica italiana. Hacía ver Isabel Paraíso cómo sus obras Sophonisba e Italia liberata da 'Goti consagran la utilización del verso suelto (verso sciolto), que trata de reproducir la grandeza del hexámetro. Por su parte, la Poetica vendría a ser la expresión de «la teoría métrica italiana más completa, sistemática y sensible escrita hasta entonces».

Reciente es la aparición de La Poética, con traducción española, en cuidada edición bilingüe, de la prestigiosa editorial Arco / Libros, en la Colección Perspectivas, que dirige la profesora María del Carmen Bobes Naves, Catedrática de Teoría de la Literatura y Literatura Comparada de la Universidad de Oviedo. En la edición, al cuidado de Isabel Paraíso, aparecen enfrentados el texto italiano y el español, en páginas pares e impares respectivamente, lo que facilita en todo momento la confrontación de la versión española con la obra original. Nadie mejor para este empeño que la profesora Paraíso, licenciada y doctora en Filología Románica, y licenciada también en Filología Italiana, que une a su exquisita sensibilidad poética una extensísima 
experiencia docente e investigadora. La traducción es impecable. La autora, que confiesa haber tenido siempre la fidelidad al texto como criterio rector, conserva en italiano todos los ejemplos propuestos por Trissino - poemas, estrofas, versos, incluso palabras aisladas- a fin de que el ejemplo concuerde con la doctrina del texto. Su traducción aparece en nota, al final del libro, junto con una amplia serie de oportunas observaciones eruditas.

El tratado de Giovan Giorgio Trissino (o Gian Giorgio, Giangiorgio, Giovanni Giorgio, nombres con los que también es conocido) consta de seis divisiones, o libros, de los cuales los cuatro primeros se publicaron en 1529, y los dos últimos, con carácter póstumo, en 1562. Se ocupan de las cuestiones métricas los libros segundo, tercero y cuarto.

El libro segundo comienza con el estudio de la «rima», entendiendo por tal lo que los griegos llaman rhythmós y los latinos numerus, «por lo cual se puede decir -apunta Trissino- que rima, ritmo y número son lo mismo». Se aduce la autoridad de Marco Tulio Cicerón, quien había expresamente indicado (Orator, 67) que se llama «número» a lo que en griego se dice «ritmo». A este respecto, cita también Trissino a Dante Alighieri (De vulgari eloquentia, II, 9) y Antonio da Tempo (Summa artis rhitimici vulgaris, II, 39), haciendo ver que de lo que él habla es específicamente del ritmo del verso. A continuación, indica que los versos se hacen con pies, los pies con sílabas, y las sílabas con letras. Por sílaba se entiende «la primera e indivisible pronunciación de la voz articulada», y necesita el «acento».

Distingue Trissino tres tipos de acento: el «espíritu», el «tiempo» y el «tono». El espíritu puede ser tenue o aspirado. La sílaba aspirada se marca con la letra $h$, que denota que «esa sílaba se profiere con más espíritu, como $a h$, interjección». En cambio, la sílaba tenue «se escribe $\sin h$, como $a$, preposición». El tiempo puede ser largo o breve. Es breve la sílaba que «se profiere en poco espacio de tiempo», y larga «la que en más», de tal manera que «se tarda tanto en proferir una sílaba larga como dos breves». Finalmente, el tono puede ser grave, agudo y circunflejo, si bien este último difiere poco del agudo. La sílaba que «se pronuncia baja» es grave, y la que «alta» es aguda. En líneas generales, puede decirse que las sílabas graves corresponden a las átonas, y las agudas a las tónicas.

Los pies son «los que gobiernan los versos», de tal manera que «casi con ellos caminan». Indica Trissino que «así como los griegos y latinos formaban sus pies con sílabas breves y largas, así nosotros los formamos con graves y agudas». Se identifica, por tanto, la sílaba 
breve con la grave, y la larga con la aguda, esto es, la sílaba breve con la átona, y la sílaba larga con la tónica. La doctrina de que en la lengua italiana, o en la española, o en otras lenguas románicas, existen sílabas largas y breves ha estado vigente hasta fechas muy cercanas. Igualmente, ha venido siendo general la creencia en una cierta equivalencia de las sílabas tónicas y las largas, así como de las átonas y las breves. Era difícil sustraerse al hechizo de las métricas clásicas. Así, Trissino insiste en que, del mismo modo que los griegos y los latinos «gobernaban sus poemas mediante los tiempos», nosotros «los gobernamos mediante los tonos». En cualquier caso, piensa el tratadista que en lengua toscana sigue habiendo sílabas largas y breves, y que «todo aquel que quiera considerar la longitud y brevedad de algunas sílabas, tanto graves como agudas, extraerá mucha utilidad de tal cosa y dará mucho ornamento a sus poemas»».

El yambo, que en la lengua griega y en la latina, consta de una primera sílaba breve y de una segunda sílaba larga, en la lengua toscana estaría formado por una primera sílaba grave (átona) y una segunda sílaba aguda (tónica), como en la palabra amor. Por su parte, el troqueo tiene la primera sílaba aguda (tónica) y la segunda grave (átona), como en la palabra tempo. Por lo que respecta al espondeo, con dos sílabas agudas (tónicas), no puede encontrarse en una palabra sola, ya que, en una palabra de dos sílabas, no pueden ser las dos tónicas. De ahí que se tome el ejemplo en dos palabras, como per far. Del mismo modo, el pirriquio, con sus dos sílabas átonas, no puede encontrarse en una palabra completa, sino en el interior de la misma, como en la palabra dolcissimo, donde simo es un pirriquio, y dolci un yambo.

Concluye el libro segundo con el estudio de la «remoción», la «colisión» y la «pronunciación conjunta», que disminuyen el verso en una sílaba, así como de las distintas «cesuras» del verso. La remoción es el fenómeno mediante el cual se remueve o elimina la última vocal a una palabra, como la $e$ de amore, que se pronuncia como amor. La colisión se produce cuando una palabra termina por vocal, y la siguiente comienza asimismo por vocal, como en el verso de Petrarca Voi, che ascoltate in rime sparse il suono (Canzoniere, I, 1). En el che ascoltate, se remueve la $e$ de che. Estaríamos en presencia del fenómeno que hoy llamamos zeuxis o sinalefa. Puede anotarse con un apóstrofo: ch'ascoltate. En este caso, se trataría más bien de una elisión. Por lo que respecta a la pronunciación conjunta, pone Trissino, entre otros ejemplos, el siguiente verso de Petrarca: Il filjuol di Latona havea gia nove (Canzoniere, XLIII, 1). Aquí la palabra havea es bisílaba, porque ve y $a$ se pronuncian conjuntamente en una sola sílaba. Se trata del fenómeno que conocemos hoy como zeuxis o sinéresis. 
El libro tercero se ocupa de las «desinencias» (rimas) y «combinaciones» (estrofas). A propósito de la rima, distingue Trissino entre versos «demediados» (agudos), «cortos» (llanos) y «plenos» (esdrújulos). En la rima de los versos demediados entra en juego únicamente la última vocal, mientras que en los versos cortos hay que tener también en cuenta la penúltima vocal y la consonante o las consonantes que estén entre la última vocal y la penúltima. Los versos plenos, por su parte, «necesitan mayor concordancia», ya que es necesario reiterar tres vocales, o más si existen diptongos, así como las consonantes implicadas.

Los versos se acoplan entre sí, formando parejas, tercetos, cuaternarios, quinarios y senarios. Hay sólo dos modos de parejas: discordes $(a, b)$ y concordes $(a, a)$. Cinco son los modos de los tercetos: $a b a, a b c$, $a b b$, $a a b, a a a$. Los modos de cuaternarios son en total quince. Entre las formas más frecuentes, aparecen $a b b a$ (lo que hoy conocemos como cuartetos y redondillas) y abab (lo que llamamos hoy serventesios y cuartetas). Siguen después los distintos modos de los quinarios, que serían al menos cincuenta y dos, y los diversos senarios.

En el libro cuarto es donde, según Isabel Paraíso, presenta Trissino «con el mayor cuidado, sensibilidad y conocimiento, el panorama de todos los tipos poemáticos usados en ese momento». Aunque se apoya en Dante y en Tempo, el tratado de Trissino supera ampliamente los modelos anteriores. Cinco son las formas que se estudian: el soneto, la balada, la canción, el madrigal y el serventese (que no corresponde al actual serventesio, sino a los tercetos encadenados y formas similares).

El soneto, cuyo nombre significa canto pequeño (canto picciolo), se compone de dos combinaciones: una de cuaternarios y otra de tercetos. Trissino llama «bases» a los cuaternarios, y «vueltas» a los tercetos, que Dante y otros autores antiguos habían denominado pies y versos respectivamente. No desconocía el tratadista el hecho de que, en la antigüedad, se habían dado casos de sonetos con tres cuaternarios. Pero Dante y Petrarca, y todos los buenos autores de aquella época, jamás hicieron uso de ellos. Los modos de cuaternarios más frecuentemente utilizados son los ya mencionados $a b b c, a b b c$, y $a b a b$, $a b a b$. En lo que concierne a los tercetos, los modos habituales son $a b c$, $a b c$; $a b c, b a c ; a b a, b a b ; a b a, a b a ; y a b b, a b b$. Escasa atención se le presta al uso combinado de versos endecasílabos y heptasílabos en el soneto, así como a las múltiples formas de los sonetos, descritos minuciosamente por Antonio da Tempo y recogidos más tarde por nuestro Juan Díaz de Rengifo, expresiones del juego de ingenio, más que de la auténtica poesía. 
Un amplio espacio dedica el libro cuarto a la balada, poema más extenso y de estructura más compleja que el soneto, así como a la canción y el madrigal. En cuanto al serventese, advierte Isabel Paraíso que el nombre italiano podría hacernos pensar en el sirventés provenzal, o en nuestro serventesio. Pero su estructura métrica es totalmente distinta. Generalmente, se trata de tercetos encadenados al estilo del modelo de Dante en la Divina comedia, pudiendo también darse otras formas encadenadas de tercetos y cuartetos.

Tres de los seis libros o divisiones de La Poética están dedicados a los estudios métricos, lo cual nos da clara noticia de la importancia que el autor otorgaba a estos saberes. Pero no menos sugestivos son los libros restantes. En el primero, se examina la lengua literaria, analizando entre otros los conceptos de claridad, verdad y belleza, todo ello sobre la base de las ideas aristotélicas. El aristotelismo está especialmente presente en los libros quinto y sexto, aparecidos póstumamente, pero escritos - como indica Isabel Paraíso- antes de 1529, fecha de la publicación de la primera parte de la obra, integrada por las cuatro primeras divisiones. En el libro quinto, se desarrollan los conceptos de imitación y catarsis, la fábula y la tragedia, los hábitos, el discurso y las palabras. El libro sexto se ocupa, por último, de los tropos y las figuras, el poema heroico, la comedia, la égloga y los demás poemas líricos.

Valioso y encomiable es, sin duda alguna, el trabajo realizado por la profesora Paraíso, autora de centenares de artículos y veintenas de libros, entre los que se pueden destacar, limitándonos al terreno del metro y el ritmo, las obras monumentales Teoría del ritmo de la prosa (1976), El verso libre hispano. Orígenes y corrientes (1985), La métrica española en su contexto románico (2000) y Reveladoras elecciones. Estudios de métrica y literatura (2007). Además de la edición de la Poética de Trissino, ha editado Estudios sobre el ritmo, de Samuel Gili Gaya (1993) y Primer Cálamo: Rítmica, de Juan Caramuel (2007). La presente obra representa la aportación de una pieza básica para el estudio de la métrica renacentista italiana, indispensable punto de referencia de las métricas europeas.

ESTEBAN TORRE Universidad de Sevilla 